\title{
Perspectiva inclusiva no contexto do ensino de engenharia e tecnologia
}

Inclusive perspective in the context of engineering and technology teaching

\author{
Perspectiva inclusiva en el contexto de la enseñanza de ingeniería y \\ tecnología
}

\section{Eliana Marques Zanata}

Professora doutora da Universidade Estadual Paulista Júlio de Mesquita Filho, São Paulo, SP, Brasil

E-mail: eliana.zanata@unesp.br ORCID: https://orcid.org/0000-0003-2345-1827

Silvia Regina Vieira da Silva

Professora doutora da Universidade Estadual Paulista Júlio de Mesquita Filho, São Paulo, SP, Brasil

E-mail: silvia.regina@unesp.br ORCID: https://orcid.org/0000-0002-1472-470X

Recebido em 12 de setembro de 2021

Aprovado em 22 de novembro de 2021

Publicado em 27 de dezembro de 2021

\section{RESUMO}

Pesquisa de abordagem qualitativa, tendo como objeto de estudo os anais do Congresso Brasileiro de Educação em Engenharia (COBENGE) dos últimos cinco anos. Este evento está relacionado à Associação Brasileira de Educação em Engenharia (ABENGE), ocorre desde $1973 \mathrm{com}$ periodicidade anual e visa promover a melhoria do ensino de graduação e pós-graduação em engenharia e tecnologia no Brasil. A opção pela análise de um congresso de educação em engenharia fundamenta-se na literatura que aborda a inclusão para além do contexto da escola básica. O objetivo foi verificar quais as possíveis discussões sobre inclusão existiam na área da Engenharia, considerada, por alguns, como "ciência dura". Foi utilizada a palavra inclusão como descritor e os resultados indicaram que o processo de inclusão, alvo de diversas pesquisas na área de Ciências Humanas, também está presente na área de Ciências Exatas, em uma associação relacionada ao ensino, destacando-se a inclusão de pessoas com deficiência e minorias, bem como a preocupação com a inclusão de mulheres, público este, até certa época na invisibilidade.

Palavras-chave: Inclusão; Ensino Superior; Engenharias.

\section{ABSTRACT}

Qualitative approach research, having as object of study the proceedings of the Brazilian Congress of Engineering Education (COBENGE) of the last five years. This event is related to the Brazilian Association of Engineering Education (ABENGE), held annually since 1973 and aims to promote the improvement of undergraduate and graduate education in engineering and technology in Brazil. The option to analyze an engineering education congress is based on the literature that addresses inclusion beyond the context of the elementary school. The objective was to verify which possible discussions about inclusion existed in the field of Engineering, considered by some as "hard science". The word inclusion 
http://dx.doi.org/10.5902/1984686X67646

was used as a descriptor and the results indicated that the inclusion process, the target of several researches in the Human Sciences area, is also present in the Exact Sciences area, in an association related to teaching, highlighting the inclusion of people with disabilities and minorities, as well as the concern with the inclusion of women, this public, until a certain time in invisibility.

Keywords: Inclusion; University Education; Engineering.

\section{RESUMEN}

Investigación de enfoque cualitativo, teniendo como objeto de estudio los anales del Congreso Brasileño de Educación en Ingeniería (COBENGE) de los últimos cinco años. Este evento está relacionado con la Asociación Brasileña de Educación en Ingeniería (ABENGE), que se realiza anualmente desde 1973 y tiene como objetivo promover la mejora de la educación de pregrado y posgrado en ingeniería y tecnología en Brasil. La opción para el análisis de un congreso de educación en ingeniería se basa en la literatura que aborda la inclusión más allá del contexto de la escuela primaria. El objetivo fue verificar qué posibles discusiones sobre inclusión existían en el campo de la Ingeniería, considerada por algunos como "ciencia dura". Se utilizó como descriptor la palabra inclusión y los resultados indicaron que el proceso de inclusión, objetivo de varias investigaciones en el área de Ciencias Humanas, también está presente en el área de Ciencias Exactas, en una asociación relacionada con la docencia, destacando la inclusión de personas con discapacidades y minorías, así como la preocupación por la inclusión de las mujeres, este público, hasta cierto momento en la invisibilidad.

Palabras clave: Inclusión; Enseñanza superior; Ingeniería.

\section{Introdução}

Abordar questões que implicam em processos inclusivos no ensino superior no contexto brasileiro se caracteriza como um avanço para a área nas últimas décadas. $\mathrm{A}$ temática inclusiva tem sido costumeiramente presente em estudos, pesquisas e práticas voltadas para a Educação Básica. Este panorama pode ser justificado tendo em vista que as políticas públicas voltadas para a inclusão escolar se intensificaram no cenário brasileiro a partir do final da década de 1990 do século passado, e, com intensidade para os anos iniciais de escolarização da população.

Desta forma, estudos, pesquisas e práticas inclusivas no contexto do ensino superior, de forma geral, só chegam a academia em meados da década de 2010, momento em que os bancos escolares universitários passam a dar visibilidade a pessoas que até então não se faziam presentes. Neste contexto, para além das pessoas que compõem o PAEE Público-alvo da Educação Especial (inclui pessoas com deficiência, transtornos globais do desenvolvimento, altas habilidades/superdotação) estão presentes as cotas que acolhem 
http://dx.doi.org/10.5902/1984686X67646

pretos, pardos, indígenas, quilombolas. Apesar da pequena representatividade, são esses alunos que começam a ter acesso ao ensino superior, por terem sido os precursores do processo inclusivo a partir da década de 1990.

A busca pela estruturação de um ambiente escolar inclusivo teve início em escolas de educação básica, as quais, historicamente, desenvolvem suas práticas pautadas em um currículo único que se propõe a alcançar todos os alunos. Contudo, na prática, o que se configura é o contrário, os alunos é que devem alcançar e dar respostas de aprendizagem frente ao currículo que ali está posto e, os atuais princípios inclusivos vêm, gradativamente, desconstruindo essa prática. Mosé (2018) frisa que no Ensino Básico, apesar de todos os problemas, existem várias ações envolvendo práticas diferenciadas da tradicional, ao contrário do Ensino Superior, ainda conservador.

A chegada dessa população ao ensino superior, incondicionalmente, desperta a necessidade de se prover condições, espaços e recursos inclusivos, os quais, até então, circundam os limites da educação básica. Pressupondo que a maior parte das práticas em sala de aula no Ensino Superior ainda são, em geral, conservadoras, como é, então, tratada a inclusão?

Frente ao exposto e com a intenção de investigar possíveis ações inclusivas, este artigo apresenta uma discussão sobre Formação e Educação Inclusiva no Ensino Superior fundamentada na sistemática de busca, seleção e leitura ostensiva de artigos publicados nos anais das cinco últimas versões do Congresso Brasileiro de Educação em Engenharia (COBENGE). Tal opção foi motivada por experiências profissionais, que serão descritas sucintamente ao longo do texto, e pela literatura relacionada ao tema, extrapolando os limites da educação básica e presentes no ensino superior.

O referido evento ocorre desde o ano de 1973, com periodicidade anual e está associado à Associação Brasileira de Educação em Engenharia (ABENGE) que disponibiliza em seu site os anais da maioria dos eventos já realizados, facilitando, assim, possíveis revisões temáticas.

\section{Referencial teórico}

A Constituição Federal Brasileira (BRASIL, 1988), fundamentada nos princípios internacionais dos direitos humanos, buscando, dentre outros, a efetivação da cidadania, a qual remete a garantia dos direitos humanos, é a primeira que se pronuncia sob princípios inclusivos, sendo ela fruto de compromissos, em consonância com acordos internacionais, 
http://dx.doi.org/10.5902/1984686X67646

dos quais o Brasil foi signatário - Convenção Interamericana para a Eliminação de Todas as Formas de Discriminação contra as Pessoas Portadoras de Deficiência (BRASIL, 2001), Declaração Universal dos Direitos Humanos (ONU, 1948), A Unesco e a Educação na América Latina e Caribe (UNESCO, 1990), Declaração Mundial de Educação para Todos (UNESCO, 1998), Declaração de Salamanca (BRASIL, 1994) - bem como impulsionando o país a aderir, posteriormente, outras políticas inclusivas, com destaque para documentos relevantes como a Lei 9.394/96 que estabelece as Diretrizes e Bases da Educação Nacional (BRASIL, 1996) e, após a LDB, destacam-se a PNEEPEI - Política Nacional de Educação Especial na Perspectiva da Educação Inclusiva (BRASIL, 2008) e recentemente, a Lei 13.146, lei Brasileira de Inclusão (BRASIL, 2015).

Dentre todos os documentos propostos, merece destaque a expressão direitos humanos, a qual está diretamente associada à criação da Organização das Nações Unidas (ONU), em 24 de outubro de 1945, em São Francisco, Estados Unidos da América (EUA), após a Segunda Guerra Mundial, quando representantes das diversas nações do mundo passaram a se reunir visando garantir a paz mundial. Mas, somente em 10 de dezembro de 1948, em uma Assembleia Geral, realizada em Paris, foi proclamada a Declaração Universal dos Direitos Humanos, Organização das Nações Unidas - ONU (1948), a qual segundo Fischmann (2001, p. 73),

[...] trata do que é básico para toda pessoa. Dignidade humana, liberdade e
justiça, direito de defesa, direito à educação, à moradia, à saúde, ao
desenvolvimento, ao trabalho, a salários dignos, ao lazer, à liberdade de
consciência, de opinião e de crença, à liberdade de associação, à
nacionalidade, ao ir e vir, à privacidade, ao acesso aos bens culturais que são
patrimônio da humanidade e de seu grupo específico, a ser respeitado
independentemente de sexo, raça/etnia, classe social, idade, religião, origem
social, enfim, sem discriminação de qualquer tipo que o exclua; a não ser
escravizado, a não ser torturado, a todos direitos e condições que permitam
que o mais básico, o direito à vida, possa ser vivido com dignidade,
participando da construção.

Portanto, com base nesta declaração, a Constituição Brasileira, (BRASIL, 1988), também fundamentada em outros documentos internacionais, pressupõe que os brasileiros deveriam ser iguais perante a lei. Assim, por exemplo, um cadeirante, ou uma pessoa com baixa (ou nenhuma) visão, deveria ter acessibilidade garantida. Um estudante com dificuldade com relação a algum conteúdo deveria receber atenção especializada visando garantir o acesso à aprendizagem. Grupos de pessoas em situação vulnerável (crianças, mulheres, homossexuais, refugiados, índios, dentre outros) deveriam ter suas necessidades atendidas, independentemente de serem alvo de campanhas visando 
http://dx.doi.org/10.5902/1984686X67646

mudança de comportamento da sociedade em relação a seus integrantes. Ou seja, através de reestruturações físicas, pedagógicas e atitudinais, ações deveriam ser tomadas de modo que fosse possível a cada sujeito exercer plenamente a sua cidadania, sendo realmente incluído na sociedade. Mas, na prática, a sociedade mundial ainda não é inclusiva; quiçá a população brasileira.

Como tais pressupostos inclusivos se relacionam com a educação escolar? A educação escolar é disciplinada pela Lei de Diretrizes e Bases da Educação Nacional 9394/96 (BRASIL, 1996) e está em consonância com a Constituição Federal, portanto, trata-se de um documento que traz os princípios inclusivos não como proposta, mas sim como política pública a ser implementada em sua totalidade.

Mesmo tendo garantido, no corpo da lei, os princípios inclusivos, os sistemas educacionais e as escolas, requerem atenção e necessitam de projetos a curto, médio e longo prazo, que promovam uma reestruturação física e a presença efetiva de profissionais especializados que possam dar suporte ao trabalho pedagógico desenvolvido. Além disso, profissionais que fazem parte do ambiente escolar necessitam de orientação e formação técnica e educacional para que sejam capazes de atender as mais diversas condições que venham colaborar para a efetivação de ambientes inclusivos. Este contexto, desejado no ambiente escolar, tanto na educação básica quanto no ensino superior, certamente, conduziria os profissionais da educação e os educandos em formação, a adquirirem posturas de respeito à diversidade e a inclusão.

Apesar de as práticas ainda não estarem totalmente de acordo com os fundamentos e princípios da inclusão, várias são as ações que visam alterar esta realidade, as quais estão presentes nos estudos que trazem, por exemplo, conceitos e práticas do desenho universal da aprendizagem para promover ambientes inclusivos (ZERBATO; MENDES, 2018; NUNES; MADUREIRA, 2021; MARCELINO; MORALES-ACOSTA, 2021).

Outros estudos têm centrado seus objetivos agregando os seis tipos de acessibilidade, em sua mais ampla dimensão, sendo elas a atitudinal, a arquitetônica, a metodológica, a instrumental, a programática e a comunicacional, sem que se marque prioridade em alguma delas. Para além do acesso por meio das matrículas regulares se torna imprescindível no Ensino Superior, assim como na Educação Básica, promover condições de permanência com qualidade e garantia de aprendizagem, ou seja, não basta estar é preciso se apropriar da estrutura. 
http://dx.doi.org/10.5902/1984686X67646

Contudo, e apesar da latência dessa necessidade, a produção acadêmica com o viés de transversalidade dos fundamentos, princípios e práticas inclusivas no ensino superior, ainda são bastante tímidos e escassos (TORRES; CALHEIROS; SANTOS, 2016; OLIVEIRA et al. 2016).

Em uma breve busca nas principais bases de dados acadêmico-científicos, no período de 2010 a 2018, sem a pretensão de se realizar um estudo de revisão, foi possível verificar que estudos têm sido desenvolvidos nas seguintes temáticas:

Quadro 1 - Recortes da Produção Científica Inclusão no Ensino Superior

\begin{tabular}{|l|l|}
\hline \multicolumn{1}{|c|}{\begin{tabular}{c}
\multicolumn{1}{|c|}{$\begin{array}{c}\text { TEMAS E ESTUDOS E } \\
\text { PESQUISAS }\end{array}$} \\
$\begin{array}{l}\text { Formação e orientação de } \\
\text { professores que atuam no ensino } \\
\text { superior }\end{array}$
\end{tabular}} & $\begin{array}{l}\text { AUTORIA/ANO DE PUBLICAÇÃO } \\
\text { Silva; Cymrot; D'antino (2012); Reis; Eufrásio; } \\
\text { Bazon (2010);Messerschmidt; Castro (2016). }\end{array}$ \\
\hline Acessibilidade comunicacional & $\begin{array}{l}\text { Domingos; Almeida; Barreto (2014); Monteiro; } \\
\text { Silveira; Ferreira (2013); Burci; Costa (2018) }\end{array}$ \\
\hline $\begin{array}{l}\text { Processos e técnicas de } \\
\text { adaptações metodológicas e ajustes } \\
\text { curriculares }\end{array}$ & $\begin{array}{l}\text { Fernandes; Costa (2015); Pansanato, } \\
\text { Rodrigues; Silva (2016). }\end{array}$ \\
\hline $\begin{array}{l}\text { Promoção de recursos de } \\
\text { acessibilidade arquitetônica }\end{array}$ & $\begin{array}{l}\text { Cambruzzi; Costa; Denari (2013); Guerreiro } \\
\text { (2012). }\end{array}$ \\
\hline $\begin{array}{l}\text { Estudos de caso } \\
\text { Ruarte; Ferreira (2010); Machado; Tres; Oliveira }\end{array}$ \\
\hline $\begin{array}{l}\text { Relatos e análises de práticas e } \\
\text { percepções de professores }\end{array}$ & $\begin{array}{l}\text { Pereira; Santos; Silva (2011); Zanfelici; Oliveira } \\
\text { (2013); Marques; Gomes (2014); Silva E Martins } \\
\text { (2016). }\end{array}$ \\
\hline
\end{tabular}

Fonte: Elaborado pelas autoras (2021).

Estes achados desnudam um desafio que ainda presente nos contextos inclusivos diz respeito ao enfrentamento e quebra de barreiras atitudinais, sendo que não se obteve devolutiva de nenhum título com essa temática.

O cenário permite a inferência que, no ensino superior, o processo de construção de um espaço inclusivo ainda é incipiente e não está pautado em políticas institucionais. Estes achados corroboram com o estudo de revisão realizado por Cabral (2017) o qual afirma que ainda se faz necessário agregar as práticas isoladas e evitar a centralidade no processo de construção de uma cultura universitária sob a perspectiva inclusiva. 
http://dx.doi.org/10.5902/1984686X67646

\section{Método}

Trata-se de uma pesquisa de abordagem qualitativa, caracterizada como estudo bibliográfico documental, tendo como objeto textos contidos nos Anais do COBENGE, nas edições de 2017 a 2021, perfazendo cinco edições do evento.

O locus da coleta de dados se deu no site da Associação Brasileira de Ensino de Engenharia (http://www.abenge.org.br/sis_artigos.php), onde estão disponíveis os resumos e textos completos referentes aos trabalhos apresentados.

Ao todo foram consultadas cinco edições do evento, sendo a última edição registrada no ano de 2021, totalizando 2674 textos disponíveis. Para a coleta dos dados foi utilizado o descritor "inclusão", e como critério de exclusão e foram descartados os artigos em que a palavra inclusão não estivesse empregada no contexto sócio educacional. Importante apontar o ano de 2018 com a maior incidência de trabalhos na área e o esvaziamento do congresso no ano 2021, provavelmente decorrente dos percalços impostos pela pandemia Covid-19, mas, contando com, pelo menos, um trabalho na área, marcando um espaço em busca de processos inclusivos. Desta forma, foram efetivamente localizados 42 trabalhos completos atendendo aos critérios prévios, representando $1,57 \%$ do total dos trabalhos apresentados nas edições analisadas. Dados completos estão descritos na Tabela 1.

Tabela 1 - Perfil dos anais das cinco edições do evento

\begin{tabular}{cccc}
\hline $\begin{array}{c}\text { Ano da } \\
\text { Edição }\end{array}$ & $\begin{array}{c}\text { Total de Artigos no } \\
\text { Anais }\end{array}$ & $\begin{array}{c}\text { Artigos sobre } \\
\text { Inclusão }\end{array}$ & $\begin{array}{c}\text { \% de artigos sobre } \\
\text { Inclusão }\end{array}$ \\
\hline 2017 & 634 & 6 & 0,95 \\
\hline 2018 & 634 & 15 & 2,53 \\
\hline 2019 & 555 & 10 & 1,98 \\
\hline 2020 & 661 & 9 & 1,36 \\
\hline 2021 & 190 & 1 & 0,53 \\
\hline TOTAL & 2674 & 41 & 1,53 \\
\hline
\end{tabular}

Fonte: Elaborada pelas autoras (2021).

A análise do material se deu por meio de quadros organizados por ano de edição da temática de abrangência do trabalho associada ao descritor inclusão. Devido à quantidade de trabalhos selecionados, os mesmos foram identificados pelos títulos e descritos nos quadros para análise, podendo ser localizados facilmente nos anais utilizando-se do mesmo procedimento descrito para a coleta de dados. Justifica-se assim a invisibilidade dos autores nas referências bibliográficas. 
http://dx.doi.org/10.5902/1984686X67646

\section{Apresentação e discussão dos resultados}

Os dados validados para análise foram organizados nos respectivos quadros correspondentes a cada edição do evento no período entre 2017 e 2021, perfazendo cinco edições.

O Quadro 2 apresenta os trabalhos do ano de 2017, nos quais é possível verificar que metade deles versa sobre a inclusão digital, dois trabalhos têm por público alvo pessoas com necessidades especiais e, apenas um trabalho teve por foco o público-alvo da educação especial, especificamente para uma pessoa com deficiência visual.

Quadro 2 - Títulos selecionados no Anais de 2017

\begin{tabular}{|c|c|}
\hline TÍTULO & ABORDAGEM \\
\hline $\begin{array}{l}\text { Uso de técnicas didáticas } \\
\text { inovadoras para } \\
\text { aprimoramento da qualidade } \\
\text { de aulas da disciplina de } \\
\text { elementos de máquinas. }\end{array}$ & $\begin{array}{l}\text { Inclusão educacional - Animações } \\
\text { tridimensionais para aprimora a compreensão e } \\
\text { visualização dos fenômenos físicos envolvendo } \\
\text { os componentes de máquinas. }\end{array}$ \\
\hline $\begin{array}{l}\text { Infosaberes: o conhecimento } \\
\text { digital como instrumento de } \\
\text { aprendiza- gens. }\end{array}$ & $\begin{array}{l}\text { Inclusão (Tecnologias Digitais) - Soluções } \\
\text { computacionais que visam melhorar a qualidade } \\
\text { de vida da comunidade em especial às pessoas } \\
\text { carentes e idosas, que compõem os excluídos } \\
\text { digitalmente. }\end{array}$ \\
\hline $\begin{array}{l}\text { Programa de educação tutorial } \\
\text { do curso de Engenharia } \\
\text { Mecânica da UFPA com a } \\
\text { universidade da terceira idade: } \\
\text { inclusão digital. }\end{array}$ & $\begin{array}{l}\text { Inclusão (Tecnologias Digitais) - Análise da } \\
\text { efetividade de um curso de inclusão digital para } \\
\text { idosos, com o objetivo de desmistificar o uso de } \\
\text { computadores e incluir estas pessoas no mundo } \\
\text { digital. }\end{array}$ \\
\hline $\begin{array}{l}\text { Inclusão digital: tornando } \\
\text { acessível às tecnologias } \\
\text { assistivas. }\end{array}$ & $\begin{array}{l}\text { Inclusão digital (Deficiência Física) - Produção de } \\
\text { mouse adaptado, de baixo custo, acessível, foca } \\
\text { sustentabilidade ao utilizar materiais recicláveis } \\
\text { de lixo eletrônico. }\end{array}$ \\
\hline $\begin{array}{l}\text { Dispositivo didático de } \\
\text { detecção de obstáculos para } \\
\text { deficientes visuais baseado } \\
\text { em lógica fuzzy embarcado } \\
\text { em plataforma arduíno. }\end{array}$ & $\begin{array}{l}\text { Inclusão (deficientes visuais) - Atenção às } \\
\text { políticas públicas de inclusão (orientação da } \\
\text { OMS e ideais dos Parâmetros Curriculares } \\
\text { Nacionais, preocupação com a aceitação do } \\
\text { usuário e produto não oneroso. }\end{array}$ \\
\hline $\begin{array}{l}\text { Processo de ensino e } \\
\text { aprendizagem em engenharia: } \\
\text { uma proposta para a } \\
\text { estruturação do ensino de } \\
\text { Física e Cálculo no curso de } \\
\text { Engenharia Civil da Uniarp. }\end{array}$ & $\begin{array}{l}\text { Inclusão (alunos com dificuldade de } \\
\text { aprendizagem) - Cartilhas nas disciplinas de } \\
\text { Física, busca sanar deficiências, refletindo o } \\
\text { respeito às necessidades pedagógicas } \\
\text { fundamentais de acadêmicos das fases iniciais } \\
\text { de um curso de engenharia civil. }\end{array}$ \\
\hline
\end{tabular}

Fonte: Elaborado pelas autoras com base nos anais do COBENG-2017 (2021).

Os trabalhos apresentados no ano de 2017 expressam o conceito de inclusão para além do olhar voltado para as pessoas que compõem o PAEE. A amplitude do termo Inclusão compreende a pessoa que demanda atenção para sanar suas necessidades, além de processos e técnicas de acolhimento para alunos com dificuldades de aprendizagem, 
http://dx.doi.org/10.5902/1984686X67646

as quais, certamente, podem beneficiar os demais alunos. Destaca-se ainda a presença de trabalhos que atendem aspectos das políticas públicas combinando acessibilidade e sustentabilidade.

Este resultado conduz à reflexão de que princípios inclusivos chegam a área sem o estigma de que inclusão é algo apenas a ser oportunizado para pessoas com alguma deficiência. Há nestes artigos uma clara proposta que amplia a abrangência do termo, corroborando com os trabalhos de Nunes; Madureira (2015, p. 130)

Torna-se evidente que a inclusão pode ser perspetivada ora como uma meta que se pretende atingir na sociedade, ora como princípio fundamental a ter como referente na intervenção educativa e pedagógica, uma vez que implica o desenvolvimento de processos que procuram garantir a alunos vulneráveis, a alunos excluídos e a alunos com NEE uma educação de qualidade, nos contextos regulares de ensino.

Em relação aos achados nos anais referentes à edição de 2018, no Quadro 3 é possível verificar um salto quantitativo na proposição de trabalhos, sendo que o número mais que dobrou, passando de seis trabalhos em 2017 para 14 trabalhos na edição de 2018.

Quadro 3 - Títulos selecionados no Anais de 2018

(continua)

\section{TÍTULO DO TRABALHO}

As políticas de democratização do acesso e as mudanças no perfil socioeconômico dos estudantes de Engenharia na UFRN.

Desenvolvimento de um projeto de extensão no município de Marabá: Incentivar a participação de Mulheres nos cursos de engenharia

O Ensino de desenho arquitetônico e a inclusão do aluno cego na universidade

\section{ABORDAGEM}

Inclusão (Lei de cotas) - Maior incidência de estudantes de escolas públicas, de pretos, pardos e indígenas, de trabalhadores e pertencentes à família com renda mensal menor que cinco salários mínimos, e diminuição de estudantes oriundos de escolas privadas, de brancos, de não trabalhadores e dos que têm renda familiar mensal maior que 5 salários.

Inclusão (mulheres no ensino superior) -Estimular no ensino médio, a aprendizagem de disciplinas de maior relevância para ciências exatas e quebrar tabus de que engenharia é profissão para homens.

Inclusão educacional (aluno cego) - Adaptação de materiais didático-pedagógicos e avaliações, aponta para condições de ensino que atendam demandas de aprendizagem que venham a favorecer a todos alunos, incluindo o aluno cego.

Inclusão Social (Pessoa com deficiência) - Elaboração colaborativa da prova de conceito de uma ferramenta para promoção do desenvolvimento visual, seguindo o Modelo de Apropriação de Resultados e o Modelo de Desenvolvimento de Prova de Conceito da PUC Campinas, para crianças com dificuldades motoras e limitações cognitivas decorrentes de paralisia cerebral. 
http://dx.doi.org/10.5902/1984686X67646

Quadro 3 - Títulos selecionados no Anais de 2018

(continua)

\section{TÍTULO DO TRABALHO}

Ferramenta para desenvolvimento visual aplicada na reabilitação de deficientes

\section{ABORDAGEM}

Inclusão Social (Pessoa com deficiência) - Elaboração colaborativa da prova de conceito de uma ferramenta para promoção do desenvolvimento visual, seguindo o Modelo de Apropriação de Resultados e o Modelo de Desenvolvimento de Prova de Conceito da PUC Campinas, para crianças com dificuldades motoras e limitações cognitivas decorrentes de paralisia cerebral.

Inclusão (Surdos) - Inclusão e acessibilidade na universidade por meio de entrevistas (representantes da instituição e estudantes surdos) com proposta de medidas para acesso aos cursos de engenharia. surdos nos cursos de engenharia da UFAM.

Inclusão Social (Tecnologias Digitais) -Destaque para políticas relacionadas à inclusão digital no desenvolvimento de projeto de ensino e extensão com o objetivo de promover o conhecimento digital, por meio de cursos de Informática para pessoas em vulnerabilidade socioeconômica e idosos.

Inclusão Educacional (cegos) - Desenvolvimento de um kit de química orgânica com modelos 3D e impressão Braille do elemento, permitindo a inclusão e acesso a estes modelos por pessoas daltônicas, de baixa visão e cegas, podendo ser utilizado por usuários com ou sem deficiência, conforme o Desenho Universal.
Mecânica assistiva: projeto de sensibilização e inclusão

O uso da linguagem de programação intuitiva para estimular o interesse de estudantes de uma periferia paraense por cursos de engenharia.

Programa de educação tutorial PET de Engenharia Civil CEFET-MG: suas atividades e contribuições para a formação alunos.

Projeto educação e arte para crianças: a transformação de uma realidade vigente.
Inclusão social (Deficiência física) - Promover uma maior inclusão social às pessoas com deficiência física, com o auxílio da Engenharia Mecânica, por meio de mudanças estruturais, procedimentais e principalmente atitudinais.

Inclusão Educacional (Tecnologias digitais) - Interação com o Ensino Médio com o objetivo de estimular estudantes da comunidade periférica a se interessarem por cursos de engenharia ou área de tecnologia por meio do ensino de linguagem de programação Scratch.

Inclusão Social PET de Engenharia Civil objetiva o compromisso com o desenvolvimento de práticas e experiências pedagógicas para a formação de um Engenheiro Civil ético, cidadão e apto a trabalhar com as demandas atuais do mercado sem perder a sensibilidade e o compromisso com as questões ambientais e a inclusão social.

Inclusão social (projeto com crianças carentes) - Alunos dos cursos de graduação enriquecem seu currículo, aprimoram a forma de lidar com pessoas e trabalham em equipe, com o objetivo de transformar a visão de mundo de crianças carentes colaborando para o processo de inclusão social. 
Quadro 3 - Títulos selecionados no Anais de 2018

(conclusão)

\section{TÍTULO DO TRABALHO}

Projeto integrador como motivador do conhecimento: uma cadeira de rodas com assistência elétrica

Projeto megatron: um novo olhar no ensino de eletrônica e empreendedorismo para o ensino médio.

SOLARIS um projeto de engenharia em ensino, pesquisa e extensão.

Tecnologias assistivas e inclusão: uma proposta para humanização no ensino de engenharia

\section{ABORDAGEM}

Inclusão Social (Acessibilidade) - Modificação mecânicoelétrica para assistência em cadeira de rodas, para liberar esforço físico em rampas ou descanso em trajetos longos.

Inclusão (acesso a Universidade) - no curso de Engenharia Elétrica ainda é notório o baixo índice de inclusão, propõe kits didáticos denominado Snap Circuits $\AA$, estimulando os alunos a ingressar nos cursos de engenharia

Inclusão Social - busca soluções de energia solar para diversos públicos visando inclusão social e educação tecnosocial, impacto positivo na formação de engenharia.

Inclusão social (Deficiência visual) - Aplicativo cadastra o código de barras de um medicamento, permitindo que o deficiente visual associe a este código, verbalmente, o respectivo nome do medicamento, período e doses de uso.

Fonte: Elaborado pelas autoras com base nos anais do COBENG-2018 (2021).

Trabalhos com a vertente centrada no público-alvo da educação especial também foram representativos somando cinco iniciativas voltadas para contextos envolvendo deficiência visual, física e surdez. Contudo, a ênfase nos trabalhos apresentados nesta edição esteve centrada na concepção de inclusão de forma geral, destacando-se o acesso e a presença de minorias no contexto universitário com um estudo sobre a Lei de Cotas e outro sobre a presença de mulheres no curso de engenharia. Destaque para a iniciativa quanto à garantia de inclusão no ensino superior decorrente da política de cotas com o envolvimento de alunos de graduação em busca de recursos inclusivos, por meio de seus conhecimentos específicos de área, indicam uma preocupação com a formação cidadã do graduando voltado para as questões inclusivas, condição esta ainda que diminuta, tende a desbravar terreno formativo cidadão.

Assim, a concepção dos princípios inclusivos voltados para o exercício da cidadania, indica que a universidade não pode se esquivar de sua cota responsabilidade nesse processo. A promoção da inclusão de minorias de do público-alvo da educação especial corrobora com a afirmativa de que "[...] a universidade deve ser espaço livre de discriminação, que favoreça a convivência com a diversidade em igualdade de condições e oportunidades" (FERNANDES, 2016, p. 1068). 
http://dx.doi.org/10.5902/1984686X67646

Os achados referentes à edição do evento realizada no ano de 2019 apontam para 11 trabalhos tendo, em sua maioria, tendo o público-alvo da educação especial em destaque, representados aqui por pessoas com deficiência visual, baixa mobilidade e surdez. Na sequência destaca-se a incidência destes e outros trabalhos que buscam promover a inclusão no contexto social, também por meio de recursos tecnológicos.

Quadro 4 - Títulos selecionados no Anais de 2019

(continua)

\section{TÍTULO}

Análise do perfil do estudante do curso de Engenharia Química no Brasil pelos dados do Enade $2014 / 2017$

\section{ABORDAGEM}

Inclusão (cotas) - Criação de cursos a distância e políticas afirmativas quanto à renda, tipo de educação básica (pública ou privada) e por cor/raça como importantes para inclusão social, no curso de Engenharia Química, de indivíduos pardos, pretos e que cursam o ensino médio em escolas públicas.

Inclusão (Tecnologia educacional - Deficiência visual) Material didático utilizado por deficientes visuais para medição de volume em experimentos químicos. Espera que soluções propostas venham a ser utilizadas nos laboratórios de química das universidades e escolas visando apoiar alunos com deficiência visual em práticas laboratoriais.
Desenvolvimento de tecnologias vas de baixo custo para auxiliar nas medidas de volume por deficientes visuais
Inclusão (Tecnologia - Surdez) - protótipo de hardware e software, intitulado Luvras - Luva Mobile, capaz de reconhecer os sinais em Libras (Língua Brasileira de Sinais) e descrevê-los em linguagem natural, por meio de sensores instalados e de um microcontrolador, os sinais são reconhecidos e transmitidos via bluetooth para um aplicativo mobile.
- Luvras - que auxilia na aprendizagem e inclusão de surdos.
Inclusão (Tecnologia educacional - Deficiência visual) Aplicação para celulares na plataforma Android que realize reconhecimento de textos, mais especificamente de números emitidos por uma balança analítica, bem como realize operações matemáticas por comandos de voz, a fim de auxiliar na inclusão em aulas de Química laboratoriais.
Leitor acessível: uma proposta de dispositivo para medidas de massa em aulas práticas de química para pessoas com deficiência visual.
Inclusão (Mulheres - gênero) - Mapear e verificar a tendência do perfil de liderança exercida por engenheiros e engenheiras e a inserção das engenheiras no mercado de trabalho nas empresas do Vale do Paraíba, localizado no interior do Estado de São Paulo.

Inclusão (Tecnologia - mulheres - gênero) - Com objetivo de promover a interdisciplinaridade, socialização e autonomia dos alunos, tem como desafios a desvinculação de atividades dependentes de kits didáticos e a inclusão de alunas em equipes de competição. 
http://dx.doi.org/10.5902/1984686X67646

Quadro 4 - Títulos selecionados no Anais de 2019

(conclusão)

\section{TÍTULO}

PET de Engenharia Civil do CEFET-MG: ações voltadas para mudanças de impacto social e valorização de novas tecnologias da construção civil.

\section{ABORDAGEM}

Inclusão (Tecnologias - social) - Compromisso com o desenvolvimento de práticas e experiências pedagógicas para a formação do Engenheiro Civil ético, cidadão e apto a trabalhar com as demandas do mercado sem perder a sensibilidade e o compromisso com as questões ambientais e a inclusão social.

Inclusão - Prática pedagógica que objetiva favorecer a inclusão e o direcionamento estudantil ao meio acadêmico durante os momentos iniciais da graduação, momento esse que se configura como um período de transição do Ensino Médio para o Ensino Superior.

Inclusão (Acessibilidade) - metodologia ativa o PBL para desenvolver protótipos sustentáveis para mobilidade de deficientes como forma de promover o conhecimento e contribuir com desenvolvimento profissional dos discentes

Inclusão (Deficiência visual) - Inclusão de um aluno deficiente visual (DV), do curso de Engenharia da Computação explicitando os recursos didáticos táteis desenvolvidos para auxiliar na aprendizagem deste aluno.

Fonte: Elaborado pelas autoras com base nos anais do COBENG-2019 (2021).

Os trabalhos apresentados neste ano abrem espaço para a constatação que a preocupação com procedimentos, processos, tecnologias e produtos propostos na área da engenharia podem ser estendidos para demais áreas do conhecimento, bem como, imprimem uma preocupação com inclusão no ensino superior.

A expertise da área das engenharias deve ser considerada um diferencial de apoio na produção e desenvolvimento tecnológico em favor da inclusão, tanto no ambiente social quanto educacional. Muito do que a área já vem desenvolvendo em busca de soluções que garantam conforto e melhoria na qualidade de vida das pessoas, certamente deverá ser aqui aplicado no campo educacional buscando dirimir barreiras e garantir condições de acessibilidade no contexto universitário, sejam elas barreiras arquitetônicas e digitais (espaços físicos e virtuais da universidade) pedagógicos (estratégias metodológicas). Segundo Malheiros; Schlünzen Junior (2020, p. 94552)

A eliminação dessas barreiras visa o reconhecimento, respeito à diferença, valorização da diversidade humana e equiparação de oportunidades no universo acadêmico. Essa visão contribui na desconstrução de situações segregacionistas. Além disso, avança em relação à ideia de equidade formal ao contextualizar as circunstâncias históricas da exclusão social e educacional. 
http://dx.doi.org/10.5902/1984686X67646

O ano de 2020 pode ser considerado um ano atípico, não só para o contexto universitário, mas para o planeta como um todo. As consequências da pandemia Covid-19 alteraram não só o modo de vida cotidiano, mas todo o modo de produção, de relacionamentos e aprendizagem. Esses reflexos foram sentidos também nos eventos científicos, os quais procuraram encontrar formas de se reinventarem para realização de forma remota, condição esta presente no material que avaliamos.

Foi registrado um aumento no número de trabalhos publicados, contudo, o mesmo não ocorreu com a incidência de trabalhos centrados nos contextos inclusivos, encontrando-se nove trabalhos para análise, conforme descrito no Quadro 5, sendo um terço deles voltado já para o contexto de ensino durante a pandemia e o uso das tecnologias digitais.

Quadro 5 - Títulos selecionados no Anais de 2020

(continua)

\section{TíTULO}

A adaptação do aluno portador de Transtorno do Espectro Autista (TEA) no Ensino Superior

Atração e retenção de alunos carentes por meio de cursos preparatórios do projeto avante.

\section{ABORDAGEM}

Inclusão TEA - Discute o cenário atual dos alunos autistas nas universidades brasileiras. Aponta medidas como a alteração dos métodos tradicionais de avaliação, a utilização de ferramentas digitais e o preparo dos professores, acompanhamento psicológico garantem ao uma adaptação mais suave, reduz a evasão e potencializa o aprendizado e interação social do educando.
Inclusão (acesso e permanência estudantil) - Apresenta a ação que realizada nas periferias com a criação de um curso preparatório ministrado com intuito de melhorar as chances de entrada de estudantes, principalmente, oriundos de escolas públicas, com condições socioeconômicas desfavoráveis.
Desenvolvimento de um aplicativo web educacional para auxiliar no ensino remoto de processamento digital de sinais.
Inclusão (Tecnologias Digitais - Surdez) - O aplicativo funciona online e o aluno pode acessar remotamente através de um link. A partir dos resultados apresentados é possível observar que o aplicativo Web apresentou um bom desempenho tanto no acesso remoto, como na aplicação de técnicas de processamento de sinais.

Inclusão - Trabalhos encontrados, que discutem a temática "eficiência energética" como agente de desenvolvimento/ inclusão social ou de solução/minimização da pobreza energética, promovendo crescimento sustentável e responsável para aquela população/localidade em estudo.

importância social do debate

Inclusão (Tecnologias digitais) - Alinhado a uma proposta de

Experimento educacional mediado por tecnologia: Libreoffice Calc sem frescura democratização da tecnologia e inclusão digital durante o período de isolamento social ofertou atividades síncronas e assíncronas, grupos de discussão, exercícios e oferta de material didático em suporte digital. 
http://dx.doi.org/10.5902/1984686X67646

Quadro 5 - Títulos selecionados no Anais de 2020

(conclusão)

\section{TÍTULO}

Ferramenta de apoio ao desenvolvimento cognitivo de deficientes.

\section{ABORDAGEM}

Inclusão (Pessoa com deficiência) - Inclusão e autonomia de PcD, numa ferramenta assistiva, baseada em conceitos de gamificação, no formato de um jogo de tabuleiro 15 células de cores e intensidade de luz ajustáveis, atende à todas as especificações, funcionais e não funcionais, esperadas pelo público alvo.

Inclusão (gênero) - desenvolver habilidades e conhecimentos de engenharia, estimulando e promovendo o incentivo da atuação feminina na área, permitem a simulação de objetos e construção de experimentos, sendo um impulsionador à inclusão das mulheres no mundo da ciência e do trabalho.

Inclusão (Mulheres- gênero) - Produz troca de saberes e a inclusão das mulheres nas engenharias, permite desenvolver potenciais e estimular uma reflexão sobre as questões sociais nas diversas escalas, ou ainda no sentido mais amplo de sua

Inclusão (Tecnologias digitais) - Podcast como uma opção viável, aplicada numa metodologia de ensino remoto assíncrona, atentando para que possuem um baixo volume de consumo de dados, facilitando a inclusão de estudantes em vulnerabilidade que tenham dificuldades no acesso a uma importância, na educação. internet banda larga ilimitada.
Uso de podcast como ferramenta pedagógica para aulas remotas durante 0 período de pandemia do COVID-19
Projeto de extensão meninas que engenham o futuro.

Fonte: Elaborado pelas autoras com base nos anais do COBENG-2020 (2021).

Analisando esta particularidade, em relação ao aumento de trabalhos voltados para recursos tecnológicos, inferimos que o processo de inclusão se faz mais presente ainda, quando os recursos tecnológicos de forma geral passam a ser utilizados buscando-se saídas para contornar as limitações impostas pela pandemia Covid-19. Espera-se nesse contexto que os avanços conquistados nesse período sejam extensivos nos anos subsequentes, promovendo e estabelecendo novas possibilidades para o acesso e permanência com qualidade no ensino superior.

Para além da questão de acesso, destaca-se ainda a presença de trabalhos voltados para o fortalecimento e conquista do espaço das mulheres nas engenharias. Ainda que sejam trabalhos pontuais no evento, esta temática tem se mantido em todas as edições, ou seja, há intencionalidade e preocupação no reconhecimento das potencialidades femininas na área.

Como um maior reflexo do cenário imposto pela pandemia Covid-19, a edição de 2021, contou com um número muito reduzido de trabalhos publicados, sendo este o menor 
http://dx.doi.org/10.5902/1984686X67646

na série analisada nas cinco últimas edições, culminando com apenas um trabalho localizado no contexto da temática da inclusão.

Em uma tentativa de busca ampliada, adicionando, por exemplo, o descritor Mulher, outros trabalhos de pesquisa foram localizados, contudo não versavam sobre questões voltadas para o contexto inclusivo universitário.

Quadro 6 - Título selecionado no Anais de 2021

\section{TÍTULO}

A inclusão de gênero no ambiente universitário por meio do IEEE WOMEN IN ENGINEERING UFBA
ABORDAGEM

Inclusão (Mulheres - gênero) - Marca a desigualdade de gênero como um grande desafio a ser combatido na atualidade, apresenta projetos para fortalecer e incentivar mulheres a ingressarem e permanecerem na área de STEM.

Fonte: Elaborado pelas autoras com base nos anais do COBENG-2021 (2021).

Assim, este único trabalho localizado versou sobre a questão de gênero, temática já presente nos anos anteriores e que busca desconstruir a ideia de que cursos de engenharia devem ser prioritários para homens. Por outro lado, o estudo recente de Machado; Machado (2021) aponta justamente que mulheres têm gradativamente alçado voos e ocupado funções no mercado de trabalho em nichos historicamente masculinos. Contudo, para que atinjam o mercado de trabalho, a formação universitária ainda apresenta demandas que precisam ser visualizadas.

[...] visualizar algumas situações vividas pelas estudantes que deixaram o espaço institucional. São questões pertinentes, que podem contribuir para a ampliação de estudos no campo, para a construção e consolidação de novas práticas institucionais no ensino superior, mas especialmente para a reflexão em torno das condições e da promoção de formação superior nas áreas de Engenharia e Tecnologias que possam incorporar o desafio da equidade de gênero ou do combate oficial à discriminação racial ou de classe como fundamentos políticos da própria formação. (KLANOVICZ; OLIVEIRA, 2021, p. 154)

A formação universitária em que as mulheres, por vezes, tendem a encontrar um ambiente ainda excludente e desconfortável deve se tornar, necessariamente, um espaço de reflexão quanto a vencer uma das barreiras mais difíceis, ou seja, a barreira atitudinal, aquela que fragiliza a pessoa acometida em um processo excludente e requer, da sociedade como um todo, mudanças de posicionamento sócio moral voltando-se para o respeito e equidade. 


\section{Considerações finais}

Os achados nesta pesquisa conduzem a duas considerações importantes. Positivamente considerando-se, por um lado, que a área das Engenharias tem enveredado esforços e dado atenção no âmbito científico, de sua produção acadêmica e de suas práticas formativas às questões que envolvem os princípios da inclusão para todos. Nesta reflexão também cabe salientar que, se essa atenção tem sido dada aos aspectos inclusivos, significa que a área tem acolhido populações que até então não faziam parte do perfil de seus profissionais, alunos e, porque não dizer, seus futuros clientes. Por outro lado, esses mesmos achados conduzem a reflexão que a incidência do público-alvo da educação especial, de pessoas com necessidades educacionais, minorias provenientes de cotas, e, ainda a presença de mulheres em uma área até poucos anos considerada prioritária para homens, ainda se faz de forma bastante tímida e diminuta frente às possibilidades.

Os achados no presente estudo demonstram a preocupação em atender não especificamente ao público-alvo da educação especial, com apenas um trabalho específico, mas sim uma concepção ampla do termo inclusão, voltada para todos que fazem parte de um contexto de aprendizagem. Esta postura se aproxima dos princípios contidos na Declaração de Salamanca datada do ano de 1994, embora tenhamos decorridos quase três décadas de sua assinatura.

Imprescindível, ao traçar essas considerações finais, atentar para o momento que o planeta está vivenciando, aproximando-se de quase dois anos no contexto da pandemia Covid-19, comprometendo todos os aspectos do desenvolvimento humano. O quadro devastador de mortes, prejuízos nos relacionamentos interpessoais, economias em queda, e o chamado por uma nova ordem social necessária com base na ciência é imprescindível para superação das fragilidades potencializadas. Nesta nova ordem social, imperativo é retomar os pressupostos de equidade social, solidariedade e inclusão em todos os espaços sociais.

\section{Referências}

ANAIS DO CONGRESSO BRASILEIRO DE ENSINO DE ENGENHARIA (2017-2021). Associação Brasileira de Ensino de Engenharia, 2021. Disponível em: http://www.abenge.org.br/sis_artigos.php. Acesso em: 05 de fev. 2021. 
http://dx.doi.org/10.5902/1984686X67646

BRASIL. Constituição da República Federativa do Brasil. Brasília: Senado, 1988. Disponível em: http://www.planalto.gov.br/ccivil_03/constituicao/constituicao.htm. Acesso em: 20 de jan. 2020.

BRASIL. Lei n. 9.394. 20 de dezembro de 1996. Lei de Diretrizes e Bases da Educação Nacional - LDB. Estabelece as diretrizes e bases da educação nacional. Disponível em: http://www.planalto.gov.br/ccivil_03/leis/L9394.htm. Acesso em: 06 dez 2019.

BRASIL. Poder Executivo. Promulga a Convenção Interamericana para a Eliminação de Todas as Formas de Discriminação contra as Pessoas Portadoras de Deficiência. Decreto no 3.956/2001. Brasil: D.O.U. 2001. Disponível em:

http://www.planalto.gov.br/ccivil_03/decreto/2001/d3956.htm. Acesso em: 12 abr 2021.

BRASIL. Ministério da Educação. Secretaria de Educação Especial (SEESP). Política Nacional de Educação Especial na Perspectiva da Educação Inclusiva. Brasília: MEC/SEESP, 2008. Disponível em:

http://portal.mec.gov.br/arquivos/pdf/politicaeducespecial.pdf. Acesso em 20 set 2019.

BRASIL. Lei 13.146, de 6 de jul. de 2015 - Lei Brasileira de Inclusão da Pessoa com Deficiência. Disponível em: http://www.planalto.gov.br/ccivil_03/_Ato20152018/2015/Lei/L13146.htm. Acesso em: 24 Abr 2017.

BURCI, Taissa Vieira Lozano; COSTA, Maria Luisa Furlan. Inclusão de pessoas com deficiência visual na educação a distância. Acta Scientiarum, v. 40, n. 2, 2018.

Disponível em:

https://www.redalyc.org/jatsRepo/3033/303357561003/303357561003.pdf. Acesso em 15 jul 2021.

CABRAL, Leonardo Santos Amâncio. Inclusão do público-alvo da Educação Especial no Ensino Superior brasileiro: histórico, políticas e práticas. Revista de Educação PUCCampinas, v. 22, n. 3, p. 371-387, 2017. Disponível em:

https://www.redalyc.org/jatsRepo/5720/572063482004/572063482004.pdf. Acesso de 15 Jul 2021.

CAMBRUZZI, Rita de Cássia Silveira; COSTA, Maria da Piedade Resende da ; DENARI, Fátima Elisabeth. Acessibilidade de um cadeirante em uma instituição pública do ensino superior: rotas e rotinas. Revista Educação Especial, Santa Maria, v.26, n.46, p. 351 366, Maio/Ago. 2013. Disponível em:

https://periodicos.ufsm.br/index.php/educacaoespecial/article/download/4386/pdf.

Acesso em 18 jul 2021.

DECLARAÇÃo Universal dos Direitos Humanos. ONU, 1948. Disponível em https://www.unicef.org/brazil/declaracao-universal-dos-direitos-humanos. Acesso em 10 Fev 2015.

DECLARAÇÃO Mundial sobre Educação para Todos e Plano de Ação para Satisfazer as Necessidades Básicas de Aprendizagem. UNESCO, 1990. Disponível em http://unesdoc.unesco.org/images/0008/000862/086291por.pdf. Acesso em 20/5/2009. 
http://dx.doi.org/10.5902/1984686X67646

DOMINGOS, Renata; ALMEIDA, Georgia Bulian Souza; BARRETO, Sônia Maria da Costa. O papel das Tecnologias de Informação e Comunicação (TICs) na inclusão de alunos com necessidades educacionais especiais no Centro Universitário do Espírito Santo - UNESC. Educação Por Escrito, Porto Alegre, v.5, n.1, p. 98-110, Jan./Jun. 2014. Disponível em https://doi.org/10.15448/2179-8435.2014.1.15857. Accesso em 15 jul 2021.

DUARTE, Emerson Rodrigues; FERREIRA, Maria Elisa Caputo . Panorama da inclusão de alunos com deficiência no ensino superior em Juiz de Fora, MG. Revista Educação Especial, Santa Maria, v.23, n.36, p. 57-72, jan./abr. 2010. Disponível em: https://periodicos.ufsm.br/educacaoespecial/article/view/1433. Acesso em 15 jan 2021.

FERNANDES, Woquiton Lima; COSTA, Carolina Severino Lopes da. Possibilidades da Tutoria de Pares para Estudantes com Deficiência Visual no Ensino Técnico e Superior. Revista Brasileira de Educação Especial, Marília, v.21, n.1, p. 39-56, Mar. 2015. Disponível em https://www.scielo.br/j/rbee/a/NdbbF87fYFSTdrRwwLB8hWP/?lang=pt\&format=html. Acesso em 20 jul 2021.

FERNANDES, Z. B. Universidade Inclusiva:(Trans) Formação e Cidadania. Journal of Research in Special Educational Needs, v. 16, p. 1067-1070, 2016. Disponível em: https://nasenjournals.onlinelibrary.wiley.com/doi/epdf/10.1111/1471-3802.12251. Acesso em 15 jul 2021.

FISCHMANN, Roseli. Educação, direitos humanos, tolerância e paz. Paidéia, Ribeirão Preto, v. 11, n. 20, p. 67-77, 2001. Disponível em:

http://www.scielo.br/pdf/paideia/v11n20/08.pdf. Acesso em: 2 set 2019.

GUERREIRO, Elaine Maria Bessa Rebello. A acessibilidade e a educação: um direito constitucional como base para um direito social da pessoa com deficiência. Revista de Educação Especial, Santa Maria, v.25, n.43, p. 217-232, Maio/Ago. 2012. Disponível em http://www.redalyc.org/articulo.oa?id=313127405004. Acesso em 15 jul. 2021.

KLANOVICZ, Luciana Rosar Fornazari; OLIVEIRA, Valéria Aparecida Monteiro de. Permanecer ou desistir? Mulheres na graduação em engenharia e tecnologias na UTFPR/Guarapuava, Brasil. Avaliação. Campinas, Vol. 26 n.01, 2021. Disponível em: https://doi.org/10.1590/S1414-40772021000100008. Acesso em: 20 jul 2021.

MACHADO, Clara Matte Borges; MACHADO, Tiara Terezinha Matte Borges. Mulheres na engenharia e decolonialismo. Brazilian Journal of Development, Curitiba, v. 7, n. 3, p24241-24256, 2021. Disponível em:

https://www.brazilianjournals.com/index.php/BRJD/article/view/26092/20686. Acesso em 20 jul 2021.

MACHADO, Maiara Bruna; TRES, Rafaela; OLIVEIRA, Lisandra Antunes de. Inserção do deficiente auditivo ou surdo no Ensino Superior da Universidade do Oeste de Santa Catarina - Campus de São Miguel do Oeste. Unoesc \& Ciência - ACHS, Joaçaba, v.2, n.2, p. 156-164, jul./dez. 2011. Disponível em: https://core.ac.uk/reader/235124700. Acesso em 15 Jul 2021. 
MALHEIRO, Cícera Aparecida Lima; SCHLÜNZEN JUNIOR, Klaus. Inclusão e acessibilidade no ensino superior brasileiro. Brazilian Journal of Development, Curitiba, v.6, n.12, p.94546-94554. 2020. Disponível em: file:///tmp/mozilla_home0/20988-53849-1PB-1.pdf. Acesso em: 15 Jul 2021.

MARCELINO, José Antonio.; MORALES-ACOSTA, Gina. Contabilidade inclusiva: didática visual e desenho universal para aprendizagem, estratégia para redução da barreira de aprendizagem. Boletim de Conjuntura (BOCA), Boa Vista, v. 5, n. 15, p. 142-154, 2021. DOI: 10.5281/zenodo.4615291. Disponível em:

http://revista.ioles.com.br/boca/index.php/revista/article/view/261. Acesso em: 20 jul. 2021.

MARQUES, Lígia da Silva; GOMES, Cláudia. Concordâncias/discordâncias acerca do processo inclusivo no Ensino Superior: um estudo exploratório. Revista Educação Especial, Santa Maria, v. 27, n.49, p. 313-326, Maio/Ago. 2014. Disponível em https://www.redalyc.org/pdf/3131/313131528004.pdf. Acesso em 15 Jul 2021.

MESSERSCHMIDT, Danieli Wayss.; CASTRO, Sabrina Fernandes de. Docência com alunos com deficiência na universidade. Journal of Research in Special Educational Needs, v. 16, p. 394-398, 2016. Disponível em: https://doi.org/10.1111/1471-3802.12165. Acesso em 14 jul. 2021.

MONTEIRO, Maria Laura da Costa.; SILVEIRA, Denis Silva da.; FERREIRA, Simone Bacellar Leal Ferreira. Universidade Aberta do Brasil: uma avaliação de acessibilidade com usuários com deficiência visual total e com baixa visão. Revista Brasileira de Administração Científica, Aquidabã, v.4, n.2, p.273-289, 2013. Disponível em: https://doi.org/10.6008/ESS2179-684X.2013.002.0019. Acesso em 18 jul 2021.

MOSÉ, V. Desafios contemporâneos: a educação. São Paulo: CPFL, 2018. 1 vídeo. Disponível em: http://www.institutocpfl.org.br/2009/12/01/integra-desafioscontemporaneos-a-educacao-viviane-mose. Acesso em: 12 dez. 2019.

NUNES, Clarisse; MADUREIRA, Isabel. Desenho Universal para a Aprendizagem: Construindo práticas pedagógicas inclusivas, Da Investigação às Práticas, vol. 5, n.2, p. 126-143. Lisboa, 2015. Disponível em: https://repositorio.ipl.pt/handle/10400.21/5211. Acesso em: 18 de julho de 2021.

OLIVEIRA, Ronaldo Queiroz de; OLIVEIRA, Silvana Maria Barros de; OLIVEIRA, Natália Almeida de; TREZZA, Maria Cristina Soares Figueiredo; RAMOS, lara Barbosa; FREITAS, Daniel Antunes. A Inclusão de Pessoas com Necessidades Especiais no Ensino Superior. Revista Brasileira de Educação Especial. Vol. 22 (2) • Apr-Jun 2016. Disponível em: https://www.scielo.br/j/rbee/a/p8wByDpCFKDtSL3SQDMTQWn/?lang=pt. Acesso em 15 de julho de 2021.

PANSANATO, Luciano Tadeu Esteves; RODRIGUES, Luzia; SILVA, Christiane Enéas. Inclusão de estudante cego em curso de Análise e Desenvolvimento de Sistemas de uma instituição pública de ensino superior: um estudo de caso. Revista Educação Especial, Marília. v. 29, n. 55, 2016. Dosponível em:

http://www.redalyc.org/articulo.oa?id=313146769017. Acesso em: 18 jul 2021. 
PEREIRA, Francilene Jane Rodrigues; SANTOS, Sérgio Ribeiro dos; SILVA, Cesar Cavalcanti da. Política de formação inclusiva: percepção de gestores sobre processo de mudanças em Instituições de Ensino Superior. Revista Brasileira de Enfermagem, Brasília, v.64, n.4. p. 711-6. Jul./Ago. 2011. Disponível em:

https://www.scielo.br/j/reben/a/Dfncfs684dhcYtsg3vxwh8S/?format=pdf\&lang=pt. Acesso em 15 Jul 2021.

REGIANI, Anelise Maria; MOL, Gerson de Souza. Inclusão de uma aluna cega em um curso de licenciatura em Química. Ciência \& Educação, Bauru, v.19, n.1, p. 123-134, 2013. Disponível em: https://doi.org/10.1590/S1516-73132013000100009. Acesso em 15 Jul 2021.

REIS, Michele Xavier dos; EUFRÁSIO, Daniela Aparecida; BAZON, Fernanda Vilhena Mafra. A formação do professor para o ensino superior: prática docente com alunos com deficiência visual. Educação em Revista, Belo Horizonte, v.26, n.1, p. 111-130, Abr. 2010. Disponível em: https://doi.org/10.1590/S0102-46982010000100006. Acesso em 16 jul 2021.

SILVA, Ane Martins; CYMROT, Raquel; D'ANTINO, Maria Eloisa Famá. Demandas de docentes do ensino superior para a formação de alunos com deficiência. Revista Brasileira de Estudos Pedagógicos. Vol. 93, n.235. Dez 2012. Disponível em: https://www.scielo.br/j/rbeped/a/sC6nPJRJvjG9KCJdDYzWZPd/abstract/?lang=pt. Acesso em 15 jul 2021.

SILVA, Kele Cristina da; MARTINS, Sandra Eli Sartoreto de Oliveira. Acessibilidade à educação superior brasileira: o que dizem os estudantes com deficiência. Journal of Research in Special Educational Needs, v. 16, n. S1, p. 116-119, 2016. Disponível em: https://nasenjournals.onlinelibrary.wiley.com/doi/full/10.1111/1471-3802.12274. Aceso em 15 Jul 2021.

TORRES; Josiane Pereira ; CALHEIROS, David dos Santos ; SANTOS, Vivian. Inclusão na educação superior brasileira: análise da produção cientifica. Interfaces da Educação, v.7, n.19, p.296-313, 2016. Disponível em: https://periodicosonline.uems.br/index.php/interfaces/article/view/1048. Acesso em 15 fev 2020.

UNESCO. Organização das Nações Unidas para a Educação, a Ciência e a Cultura. A Unesco e a Educação na América Latina e Caribe (1987-1997). Chile: Unesco. 1998. Disponível em: http://www.dominiopublico.gov.br/download/texto/ue000294.pdf. Acesso em 10 Fev 2014.

ZANFELICI, T. O.; OLIVEIRA, S. L. M. Ensino de testes psicológicos a alunos com deficiências sensoriais: expectativas e experiências. Avaliação Psicológica:

Interamerican Journal of Psychological Assessment. Vol. 12, n.3, p.369-378, 2013. Disponível em: https://dialnet.unirioja.es/servlet/articulo?codigo=5118597. Acesso em 15 Jul 2021. 
ZERBATO, Ana Paula; Mendes, Enicéia Gonçalves. Desenho universal para a aprendizagem como estratégia de inclusão escolar. Educação. Unisinos, vol. 22, n. 2, 2018, Abril-Junho, p. 147-155. Universidade do Vale do Rio dos Sinos. Disponível em: https://www.redalyc.org/articulo.oa?id=449657611004. Acesso em: 15 de junho de 2021.

(c) (1) (3) International (CC BY-NC 4.0) 